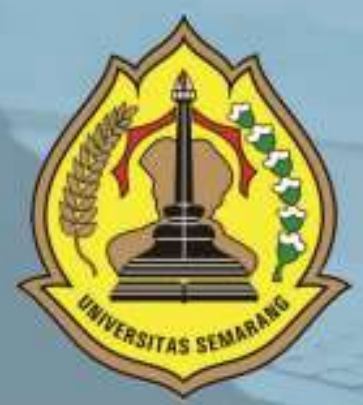

PENGARUH WORK FAMILY CONFLICT, STRES KERJA DAN KEPEMIMPINAN TERHADAP TURNOVER INTENTION KARYAWAN (STUDI PADA SELURUH KARYAWAN BAGIAN PLANNING PRODUCTION AND INVENTORY CONTROL PT. PARKLAND WORLD INDONESIA JEPARA

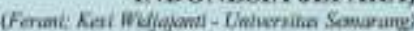

STUDI SOFT SKILL LULUSAN PENDIDIKAN KEJURUAN DI TEMPAT KERJA

Whort-Chiversikio Semorang

ANALISIS IINGKUNGAN INTERNAL DAN EKSTERNAL, PADA UKM PREMIUM PLUS LAUNDRY CABANG MULAWARMAN SEMARANG

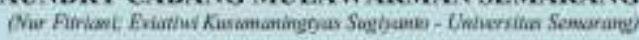

FAKTOR-FAKTOR YANG MEMPENGARUHI PERTIMBANGAN TINGKAT MATERIALITAS AUDIT

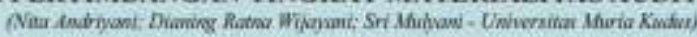

MANAJEMEN LABA DAN FAKTOR-FAKTOR YANG MEMPENGARUHINYA (STUDI EMPIRIS PADA PERUSAHAN MANUFAKTUR DI BEI)

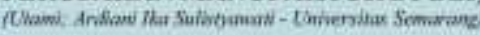

PENDAPATAN ASLI DAERAH, DANA PERIMBANGAN, DAN SISA LEBIH PEMBIAYAAN ANGGARAN TERHADAP PENGALOKASIAN BELANJA MODAL: STUDI PADA KABUPATEN/KOTA DI PROVINSI JAWA TENGAH

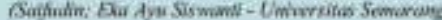

PERSEPSI PENGGUNA JASA TRANS JATENG TERHADAP KUALITAS PELAYANAN ANGKUTAN AGLOMERASI PERKOTAAN TRANS

JATENG

(Studi Kasus Trans Jateng Koridor I Semarang (Tawang) - Bawen)

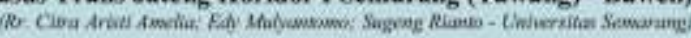

WORTHLESSNESS IS A POWER: MENGAPA ORANG BERSEDIA MENARUH UANG DI APLIKASI GO-PAY

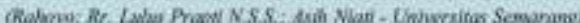

ANALISIS PENGARUH KUALITAS PRODUK, PERSEPSI HARGA, DAN PROMOSI TERHADAP KEPUTUSAN PEMBEIIAN WELLBLUE AL KALINE WATER PITCHER

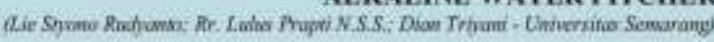

STRATEGI PEMASARAN UNTUK MENINGKATKAN VOLUME PENJUALAN (STUDI KASUS PADA SHOFA CATERING)

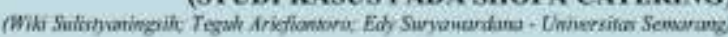

PENGARUH CITRA MEREK, PERSEPSI HARGA, DAN KUALITAS PRODUK TERHADAP KEPUTUSAN PEMBELIAN SEPATU OLAH RAGA MEREK ADIDAS

(Studi di Kota Semarang)

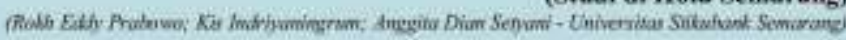

PENGARUH KEMUDAHAN TERHADAP KEPUTUSAN MENGGUNAKAN E-BANKING PADA BNI 46 KC KARANGAYU SEMARANG DENGAN MINAT NASABAH DAN KEPERCAYAAN SEBAGAI VARIABEL. MEDIASI

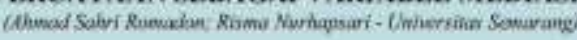

PENELITLAN KEBERLANGSUNGAN USAHA ARDANI INDONESIA SEBAGAI UMKM BERBASIS INDUSTRI KREATIF

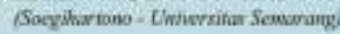

STRATEGI PELAYANAN BUS RAPID TRANSIT (BRT) TRANS SEMARANG

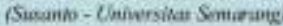

ANALISIS PENGARUH KEPEMIMPINAN, STRES KERJA, DAN LINGKUNGAN KERJA TERHADAP KINERJA KARYAWAN BAGIAN PRODUKSI SEWING PT. SAMWON BUSANA INDONESIA SEMARANG

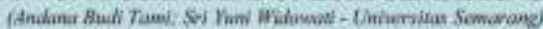




\section{DESKRIPSI}

Majalah IImiah Solusi Mengkaji

Masalah-Masalah Sosial,

Ekonomi dan Bisnis

\section{KETERANGAN TERBIT}

Terbit Pertama Kali Juli 2002

dan SelanjutnyaTerbit Tiga Bulan

Sekali (Januari, April, Juli dan

Oktober)

\section{PENERBIT}

Fakultas Ekonomi USM

\section{ALAMAT PENERBIT}

JL. Soekarno Hatta Semarang

Telp. 024-6702757 Fax. 024-6702272

\section{PENGELOLA}

Editor in Chief : Yohanes Suhardjo, SE, M.Si., Ak, CA Vice Editor Chief : Sugeng Rianto, SE, MM

Managing Editor: Edy Suryawardana, SE, MM

Secretary of Managing Editor : Asih Niati, SE, MM

Administration \& Circulation :

Citra Rizkiana, SE, MM

Layout \& Typesetting : M Burhan Hanif S.Kom, M.Kom

Board of Editors:

1. Prof. Dr. Ir. Kesi Widjajanti, SE, MM (USM)

2. Prof. Drs. Mohammad Nasir, Msi, Ph.D, AK. (USM)

3. Prof. Supramono SE, MBA, DBA (UKSW)

4. Prof. Drs. H. Imam Ghozali, M.Com, Akt, PhD (UNDIP)

5. Prof. Dr. Agus Suroso, MS (UNSOED)

6. Prof. Dr. Widodo, SE, M.Si (UNISSULA)

7. Prof. Dr. Dra. Sulastri, ME, M.Kom (UNSRI)

8. Dr. Ardiani Ika S, SE, MM, Ak, CA, CPA (USM)

\section{KATA PENGANTAR}

Sungguh merupakan kebahagiaan tersendiri bagi kami, takala kami dapat hadir rutin setiap tiga bulan sekali untuk saling bertukar pikiran mengenai hal-hal baru dibidang sosial, ekonomi dan bisnis.

Pada kesempatan ini penerbit menyampaikan terima kasih kepada semua pihak yang telah mengirimkan artikel-artikelnya. Penerbit akan membuka kesempatan seluas-luasnya bagi seluruh kalangan akademisi maupun praktisi baik dari dalam maupun luar Universitas Semarang untuk mempublikasikan karya ilmiahnya.

Penerbitan majalah ilmiah "SOLUSI" kali ini menghadirkan 15 (Lima Belas) artikel yang kami anggap layak untuk diterbitkan, dengan harapan dapat menjadi tambahan referensi bagi para pembaca dan menjadi sumbangan pengembangan persemaian khasanah pengetahuan dibidang sosial, ekonomi dan bisnis.

Akhir kata semoga majalah ilmiah "SOLUSI" dapat memberi manfaat yang sebesar-besarnya.

Hormat Kami 


\section{DAFTAR ISI}

PENGARUH WORK FAMILY CONFLICT, STRES KERJA DAN KEPEMIMPINAN TERHADAP TURNOVER INTENTION KARYAWAN (STUDI PADA SELURUH KARYAWAN BAGIAN PLANNING PRODUCTION AND INVENTORY CONTROL PT. PARKLAND WORLD INDONESIA JEPARA)

(Ferani; Kesi Widjajanti - Universitas Semarang)

STUDI SOFT SKILL LULUSAN PENDIDIKAN KEJURUAN DI TEMPAT KERJA

(Albert - Universitas Semarang)...

ANALISIS LINGKUNGAN INTERNAL DAN EKSTERNAL PADA UKM PREMIUM PLUS

LAUNDRY CABANG MULAWARMAN SEMARANG

(Nur Fitriani; Eviatiwi Kusumaningtyas Sugiyanto - Universitas Semarang)

FAKTOR-FAKTOR YANG MEMPENGARUHI PERTIMBANGAN TINGKAT

MATERIALITAS AUDIT

(Nita Andriyani; Dianing Ratna Wijayani; Sri Mulyani - Universitas Muria Kudus).

MANAJEMEN LABA DAN FAKTOR-FAKTOR YANG MEMPENGARUHINYA

(STUDI EMPIRIS PADA PERUSAHAN MANUFAKTUR DI BEI)

(Utami; Ardiani Ika Sulistyawati - Universitas Semarang)

PENDAPATAN ASLI DAERAH, DANA PERIMBANGAN, DAN SISA LEBIH PEMBIAYAAN ANGGARAN TERHADAP PENGALOKASIAN BELANJA MODAL: STUDI PADA

KABUPATEN/KOTA DI PROVINSI JAWA TENGAH

(Saifudin; Eka Ayu Siswanti - Universitas Semarang).

PERSEPSI PENGGUNA JASA TRANS JATENG TERHADAP KUALITAS PELAYANAN ANGKUTAN AGLOMERASI PERKOTAAN TRANS JATENG

(Studi Kasus Trans Jateng Koridor I Semarang (Tawang) - Bawen)

(Rr. Citra Aristi Amelia; Edy Mulyantomo; Sugeng Rianto - Universitas Semarang)

WORTHLESSNESS IS A POWER: MENGAPA ORANG BERSEDIA MENARUH UANG DI APLIKASI GO-PAY

(Rahoyo; Rr. Lulus Prapti N.S.S.; Asih Niati - Universitas Semarang).

ANALISIS PENGARUH KUALITAS PRODUK, PERSEPSI HARGA, DAN PROMOSI TERHADAP KEPUTUSAN PEMBELIAN WELLBLUE ALKALINE WATER PITCHER

STRATEGI PEMASARAN UNTUK MENINGKATKAN VOLUME PENJUALAN (STUDI KASUS PADA SHOFA CATERING)

(Wiki Sulistyaningsih; Teguh Ariefiantoro; Edy Suryawardana - Universitas Semarang)

PENGARUH CITRA MEREK, PERSEPSI HARGA, DAN KUALITAS PRODUK TERHADAP KEPUTUSAN PEMBELIAN SEPATU OLAH RAGA MEREK ADIDAS

(Studi di Kota Semarang)

(Rokh Eddy Prabowo; Kis Indriyaningrum; Anggita Dian Setyani - Universitas Stikubank Semarang) .121

PENGARUH KEMUDAHAN TERHADAP KEPUTUSAN MENGGUNAKAN E-BANKING PADA BNI 46 KC KARANGAYU SEMARANG DENGAN MINAT NASABAH DAN KEPERCAYAAN SEBAGAI VARIABEL MEDIASI

(Ahmad Sahri Romadon; Risma Nurhapsari - Universitas Semarang) 
PENELITIAN KEBERLANGSUNGAN USAHA ARDANI INDONESIA SEBAGAI UMKM BERBASIS INDUSTRI KREATIF

(Soegihartono - Universitas Semarang)

STRATEGI PELAYANAN BUS RAPID TRANSIT (BRT) TRANS SEMARANG

(Susanto - Universitas Semarang).....

ANALISIS PENGARUH KEPEMIMPINAN, STRES KERJA, DAN LINGKUNGAN KERJA TERHADAP KINERJA KARYAWAN BAGIAN PRODUKSI SEWING PT. SAMWON BUSANA INDONESIA SEMARANG

(Andana Budi Tami; Sri Yuni Widowati - Universitas Semarang). 


\title{
ANALISIS PENGARUH KUALITAS PRODUK, PERSEPSI HARGA, DAN PROMOSI TERHADAP KEPUTUSAN PEMBELIAN WELLBLUE ALKALINE WATER PITCHER
}

\author{
Lie Styono Rudyanto \\ Rr. Lulus Prapti N.S.S. \\ Dian Triyani
}

Fakultas Ekonomi Universitas Semarang

Diterima: Agustus 2020, Disetujui: September 2020, Dipublikasikan: Oktober 2020

\begin{abstract}
Today, the growing business world, encouraging entrepreneurs to increasingly tight competition in various business sectors. One of them is in the health drinking water filter industry sector in Indonesia. Companies that look at this sector, one of which is CV Mitra Kasih Perkasa by presenting the Wellblue Alkaline Water Pitcher as a maker of health drinking water. Therefore this study aims to analyze the effect of product quality, price perception, and promotion on purchasing decisions

The population in this study were all unknown Wellblue Alkaline Water Pitcher buyers, with a total sample of 96 respondents. The sampling technique using probability sampling used is the type of simple random sampling. Data analysis techniques using the validity test, reliability test, classic assumption test, multiple linear regression analysis, and hypothesis testing using $t$ test and $F$ test, analysis of the coefficient of determination (R2).

The results of this study indicate that product quality, price perception, and promotion have a positive effect on purchasing decisions. Based on the coefficient of determination (R2) of 59.5\% the purchase decision variable Wellblue Alkaline Water Pitcher is influenced by Product Quality, Price Perception, and Promotion.
\end{abstract}

Keywords: Product Quality, Price Perception, Promotion, Purchasing Decisions

\begin{abstract}
ABSTRAK
Dewasa ini, dunia usaha yang semakin berkembang, mendorong para pengusaha untuk semakin bersaing ketat diberbagai sektor usaha. Salah satunya adalah disektor industri filter air minum kesehatan di Indonesia. Perusahaan yang melirik sektor ini, salah satunya adalah CV Mitra Kasih Perkasa dengan menghadirkan Wellblue Alkaline Water Pitcher sebagai alat pembuat air minum kesehatan. Oleh karena itu penelitian ini bertujuan untuk menganalisa pengaruh kualitas produk, persepsi harga, dan promosi terhadap keputusan pembelian.

Populasi dalam penelitian ini adalah seluruh pembeli Wellblue Alkaline Water Pitcher yang tidak diketahui jumlahnya, dengan jumlah sampel 96 responden. Teknik
\end{abstract}


pengambilan sampel menggunakan probability sampling yang digunakan digunakan adalah jenis simple random sampling. Teknik analisis data menggunakan uji validitas, uji reliabilitas, uji asumsi klasik, analisis regresi linier berganda, serta pengujian hipotesis menggunakan uji $\mathrm{t}$ dan uji $\mathrm{F}$, analisis koefisien determinasi $\left(\mathrm{R}^{2}\right)$.

Hasil penelitian ini menunjukan bahwa kualitas produk, persepsi harga, dan promosi berpengaruh positif terhadap keputusan pembelian. Berdasarkan nilai koefisien determinasi $\left(\mathrm{R}^{2}\right)$ sebesar 59,5\% variabel keputusan pembelian Wellblue Alkaline Water Pitcher dipengaruhi oleh Kualitas Produk, Persepsi Harga, dan Promosi.

Kata Kunci : Kualitas Produk, Persepsi harga, Promosi, Keputusan Pembelian

\section{LATAR BELAKANG}

Keputusan pembelian merupakan hal yang sangat penting untuk diperhatikan karena hal tersebut berguna untuk menyusun strategi pemasaran bagi sebuah perusahaan. Menurut Kotler (2002), Keputusan pembelian adalah tindakan calon konsumen untuk menentukan membeli sebuah produk atau tidak. Tentunya konsumen akan mempertimbangkan beberapa faktor seperti kualitas produk, persepsi harga, dan promosi atas produk/jasa yang akan dibelinya. Alternatif pilihan konsumen akan menghasilkan manfaat yang diharapkan memenuhi dan memuaskan kebutuhan dan keinginannya. Keputusan pembelian menurut Kotler (2012) merupakan seleksi terhadap dua pilihan alternatif atau lebih, dengan kata lain ketersediaan pilihan alternatif yang ada merupakan suatu keharusan dalam pengambilan keputusan pembelian.

Berdasarkan pernyataan diatas dapat diketahui bahwa keputusan pembelian merupakan proses pemilihan berbagai alternatif cara guna menyelesaikan masalah atau kebutuhan pasar. Pelanggan dengan sendirinya akan menyimpulkan informasi yang didapatnya dan memberikan keputusan pembelian atas informasi yang didapatnya. Selain pendapat para ahli, hal ini dibuktikan pula pada penelitian milik Baruna Hadi Brata, Shilvana Hussani, dan Hapzi Ali yang berjudul "The Influence of Quality Product, Price, Promotion, and Location tp Product Purchase Decision on Nitchi at PT. Jaya Swarasa Agung in Central Jakarta" menghasilkan bahwa terdapat pengaruh positif Kualitas produk, harga, dan promosi terhadap keputusan pembelian oleh pelanggan.

Menurut Daryanto (2012) "Kualitas dapat diartikan sebagai kemampuan suatu produk ataupun jasa dalam memenuhi kebutuhan konsumen". Kualitas produk sangatlah berpengaruh dalam pemasaran sebuah produk, apabila produk yang ditawarkan memiliki kualitas yang baik, maka konsumen tidak akan segan untuk segera mengambil keputusan pembelian atas produk tersebut, dan akan berdampak positif bagi peningkatan omset yang dapat memberikan keuntungan bagi perusahaan. Kotler dan Amstrong (2008) berpendapat bahwa ketika kualitas produk semakin meningkat, maka akan memberikan kesempatan kepada pelanggan untuk memberikan keputusan pembelian. Hal tersebut didukung dengan penelitian yang berhubungan dengan beberapa faktor 
yang mempengaruhi keputusan pembelian. Menurut penelitian yang dilakukan oleh Sarini Kodu (2013) yang berjudul "Harga, Kualitas Produk, dan Kualitas Pelayanan Pengaruhnya Terhadap Keputusan Pembelian Mobil Toyota Avanza", menyatakan bahwa Harga, kualitas produk, dan kualitas pelayanan secara simultan berpengaruh signifikan terhadap keputusan pembelian.

Selain kualitas produk yang diutamakan bagi perusahaan, harga dari sebuah produk juga tidak boleh dikesampingkan. Persepsi merupakan kegiatan yang dilakukan pasar untuk memilih, mengorganisir, dan mengartikan informasi yang didapatnya agar memiliki gambaran tentang sebuah produk Kotler dan Keller $(2009,126)$. Bedasarkan informasi tersebut maka dapat diartikan bahwa persepsi harga tercipta atas dasar infromasi yang didengar, dilihat, dan yang didapatkannya, maka akan terbentuklah sebuah harga yang sesuai dengan manfaat yang akan diterima konsumen. Hal ini juga didukung oleh penelitian yang dilakukan oleh Achmad Jamaludin, Zainul Arifin, Kadarismasn Hidayat (2015) yang berjudul tentang "Pengaruh Promosi Online dan Persepsi Harga Terhadap Keputusan Pembelian”, yang menyatakan bahwa promosi online dan persepsi harga secara bersama-sama berpengaruh signifikan terhadap keputusan pembelian.

Menurut Kotler dan Keller (2009 : 219) menyatakan bahwa promosi merupakan kegiatan utama dalam melakukan kampanye pemasaran, yang menggunakan berbagai instumen, guna merangsang pelanggan dan pedagang agar melakukan pembelian yang lebih cepat atau lebih besar. Berdasarkan informasi diatas maka, dapat disimpulkan bahwa promosi merupakan bahan inti dalam dunia pemasaran, yang burtujuan untuk meberikan informasi kepada seluruh calon pelanggan dan menstimulasi calon pelanggan untuk segera memberikan keputusan pembelian. Hal ini didukung oleh penelitian yang dilakukan oleh Charlie Bernando Halomoan Samosir dan Arief Bowo Prayoga K (2015) yang berjudul "Jurnal Pengaruh Persepsi Harga dan Promosi terhadap Keputusan Pembelian Konsumen Produk Enervon-C" menghasilkan bahwa terdapat pengaruh yang positif ssignifikan dari persepsi harga dan promosi terhadap keputusan pembelian konsumen.

Salah satu perusahaan yang menjualkan dan mendistribusikan alat penyaring air minum kesehatan Wellblue Alkaline Water Pitcher adalah CV Mitra Kasih Perkasa, yang berlokasi di Kota Semarang. CV Mitra Kasih Perkasa memiliki target omset penjualan sebesar Rp 300.000.000 tiap bulannya, dan di tahun 2017 dan 2018 yang tidak mencapai target omset penjualan, Bahkan di menjelang akhir tahun 2019, dari hasil penjualan Wellblue Alkaline Water Pitcher mengalami penurunan omset yang cukup signifikan. Dari fenomena tersebut, peneliti mengamati apa saja faktor-faktor yang mempengaruhi keputusan pembelian pada produk Wellblue Alkaline Water Pitcher.

Berdasarkan pernyataan diatas ketika calon pembeli hendak mengambil keputusan dalam pembelian tentunya, calon pembeli akan mencari informasi tentang produk dan mengevaluasi produk tersebut mulai dari sisi kualitas produk dan ketahanan produk itu sendiri, serta calon pembeli tentunya akan mengevaluasi apakah produk 
tersebut memiliki harga yang terjangkau serta sesuai dengan kualitas produk yang diterimanya. Dan ketika perusahaan sering melakukan promosi tentunya akan banyak calon pembeli yang mendapatkan informasi tentang Wellblue Alkaline Water Pitcher. Semakin banyak keputusan pembelian yang diambil oleh para calon pembeli, maka hal ini dapat meningkatkan omset penjualan Wellblue Alkaline Water Pitcher. Oleh karena itu timbul keinginan dari peneliti untuk mengambil judul "Analisis Pengaruh Kualitas Produk, Persepsi Harga dan Promosi Terhadap Keputusan Pembelian Wellblue Alkaline Water Pitcher."

\section{Rumusan Masalah}

Menurut latar belakang yang telah dijabarkan, terdapat fenomena dimana tidak tercapainya target penjualan tahun 2017-2019 oleh perusahaan CV Mitra Kasih Perkasa. Maka perumusan masalah dalam penelitian ini adalah; Bagaimana meningkatkan omset penjualan perusahaan. Oleh sebab itu muncul beberapa pertanyaan penelitian antara lain:

1. Bagaimana pengaruh kualitas produk terhadap keputusan pembelian Wellblue Alkaline Water Pitcher?

2. Bagaimana pengaruh persepsi harga terhadap keputusan pembelian Wellblue Alkaline Water Pitcher?

3. Bagaimana pengaruh promosi terhadap keputusan pembelian Wellblue Alkaline Water Pitcher?

\section{HUBUNGAN LOGIS ANTAR VARIABEL DAN PERUMUSAN HIPOTESIS Hubungan kualitas produk terhadap keputusan pembelian}

Pengertian kualitas produk menurut Kotler (2012), yaitu kualitas produk merupakan ciri-ciri atau sifat dari suatu barang dan jasa yang berpengaruh pada kepuasan atas kebutuhan yang dinyatakan dinyatakan/tersirat.

Kotler dan Armstrong (2002) berpendapat bahwa keputusan pembelian adalah proses pengambilan keputusan yang dilakukan oleh pembeli untuk membeli suatu produk atau jasa yang ditawarkan kepadanya.

Dalam penelitian yang dilakukan oleh Baruna Hadi Brata, Shilvana Husani dan Hapzi Ali (2017) menunjukan bahwa kualitas produk berpengaruh positif terhadap keputusan pembelian. Hal ini sejalan dengan penelitian yang dilakukan oleh Sarini Kodu (2013) yang menunjukan kualitas produk berpengaruh positif terhadap keputusan pembelian. Berdasarkan uraian tersebut maka hipotesis yang dapat dirumuskan ialah sebagai berikut :

H1 : Kualitas Produk berpengaruh positif terhadap Keputusan Pembelian. 


\section{Hubungan persepsi harga terhadap keputusan pembelian}

Menurut Kotler dan Keller (2009) harga merupakan salah satu elemen dari bauran pemasaran. Perusahaan biasanya menetapkan suatu harga berdasarkan jumlah permintaan, biaya berdasarkan letak geografis, kebutuhan segmen pasar, waktu pembelian, tingkat pemesanan, jumlah pengiriman, garansi, dan lain-lain. Persepsi harga yang ada dibenak konsumen adalah prioritas utama sebuah perusahaan dalam memasarkan produk atau jasa yang ditawarkannya.

Kotler dan Keller (2009) berpendapat bahwa keputusan pembelian merupakan proses dalam menganalisa kebutuhan dan keinginan, informasi produk, dan penilaian terhadap alternatif produk, keputusan pembelian dan perilaku purna pembelian.

Hasil penelitain Charlie Bernando Halomoan Samosir, Arief Bowo Prayoga K. (2015) yang sejalan dengan Sarini Kodu (2013) menemukan bahwa variabel persepsi harga berpengaruh positif terhadap keputusan pembelian. Berdasarkan uraian diatas maka hipotesis yang dirumuskan adalah:

H2 : Persepsi Harga berpengaruh positif terhadap Keputusan Pembelian.

\section{Hubungan promosi terhadap keputusan pembelian}

Promosi merupakan hal terpenting dalam perusahaan untuk menginformasikan produknya kepada konsumen (Anggarisma, 2015). Promosi merupakan salah satu elemen terpenting dalam kegiatan pemasaran suatu perusahaan, namun promosi bukan hanya sebagai alat untuk mengkomunikasikan produk atau jasanya kepada calon konsumen, tetapi juga merupakan alat untuk mempengaruhi calon konsumen agar dapat segera mengambil keputusan pembelian.

Promosi digunakan untuk menyampaikan informasi tentang produk atau jasa yang ditawarkan perusahaan kepada khalayak umum agar calon konsumen mengetahui keberadaan produk atau jasa tersebut dan nantinya bisa saja calon konsumen akan tertarik uktuk membeli produk tersebut.

Keputusan pembelian merupakan proses dimana pembeli benar-benar mengambil keputusan untuk membeli suatu produk dan menggunakan barang yang ditawarkan kepadanya (Kotler dan Armstrong, 2002).

Berdasarkan penelitian yang dilakukan oleh Sarini Kodu (2013) dengan judul "Harga, Kualitas Produk, dan Kualitas Pelayanan Pengaruhnya Terhadap Keputusan Pembelian Mobil Toyota Avanza" bahwa variabel promosi berpengaruh positif terhadap keputusan pembelian dan penelitian yang dilakukan oleh Charlie Bernando Halomoan Samosir, Arief Bowo Prayoga K. (2013) yang berjudul "Jurnal Pengaruh Persepsi Harga dan Promosi Terhadap Pembelian Konsumen Produk Enervon-C" dapat diambil kesimpulan bahwa variabel promosi berpengaruh positif terhadap variabel keputusan pembelian. Berdasarkan uraian diatas maka hipotesis yang dapat dirumuskan adalah:

\section{H3 : Promosi berpengaruh positif terhadap Keputusan Pembelian}




\section{Kerangka Pemikiran}

\section{Kerangka Pemikiran Teoritis}

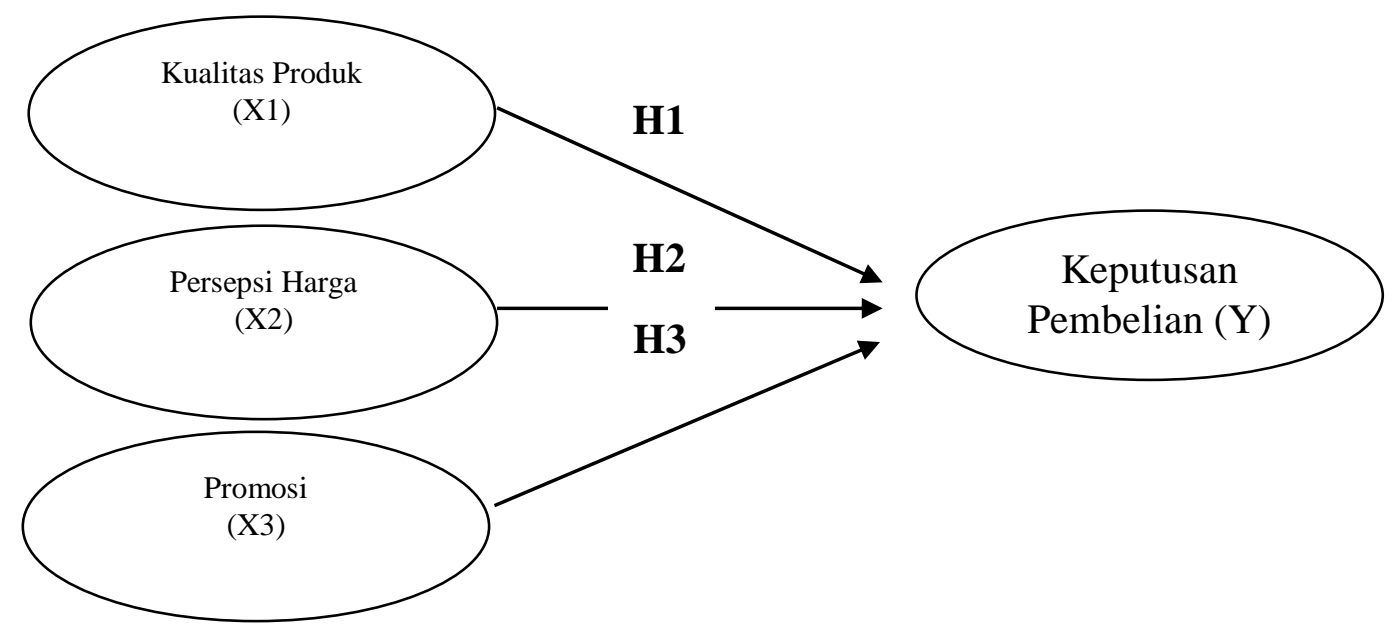

\section{OBJEK PENELITIAN DAN UNIT SAMPEL}

Objek yang digunakan dalam penelitian ini adalah Wellblue Alkaline Water Pitcher yang didistribusikan di Indonesia oleh CV Mitra Kasih Perkasa. Unit Sampel yang digunakan yaitu konsumen yang melakukan pembelian produk Wellblue Alkaline Water Pitcher.

\section{Populasi dan Penentuan Sampel}

\section{Populasi}

Menurut Ferdinand (2013) populasi adalah gabungan dari elemen elemen yang berupa kejadian, hal atau orang yang memiliki karakteristik serupa dan menjadi pusat penelitian bagi seorang peneliti. Populasi dalam penelitian ini ialah seluruh konsumen yang membeli dan menggunakan produk Wellblue Alkaline Water Pitcher yang jumlahnya tidak diketahui.

\section{Sampel}

Ferdinand (2013) menyatakan bahwa sampel merupakan subset dari beberapa anggota populasi. Subset diambil karena peneliti tidak mungkin dapat meneliti seluruh anggota populasi, oleh sebab itu peneliti membentuk sampel yang merupakan perwakilan populasi. Dengan meneliti sampel seorang peneliti dapat meng-generalisasi untuk seluruh populasi.

Pengambilan sampel dalam penelitian ini dengan pertimbangan, peneliti tidak mungkin dapat meneliti semua populasi yang ada, karena jumlahnya yang sangat banyak. Sehingga teknik pengambilan sampel dalam penelitian ini menggunakan probability sampling. Jenis probability sampling yang digunakan adalah jenis simple random sampling, dimana peneliti yang menentukan sendiri responden secara acak dan memilih anggota populasi yang dianggap dapat 
memberikan informasi yang diperlukan oleh peneliti. Responden yang dipilih dalam penelitian ini adalah konsumen Wellblue Alkaline Water Pitcher.

Pada penelitian ini, tidak diketahui jumlah populasinya, oleh sebab itu untuk menentukan ukuran sampel penelitian dapat menggunakan rumus sebagai berikut (Leedy dan Arikunto, 1006 : 136) sebagai berikut :

$$
N=\frac{(Z)^{2}}{e}(P)(1-P)
$$

Keterangan :

$\mathrm{N}$ = Besarnya sampel yang diperlukan

$\mathrm{P}=$ Perkiraan proporsi pada populasi jika tidak diketahui, maka nilai $\mathrm{P}$ (1-P) ditaksir dengan nilai maksimal 0,25

$\mathrm{Z}=$ Nilai standar sesuai dengan tingkat signifikan, dalam penelitian ini nilai $\mathrm{Z}$ yang ditetapkan adalah confidance level $95 \%$ adalah 1,96

$\mathrm{E}=$ Kesalahan penafsiran maksimal (yang dapat diterima) dengan menggunakan confidance level $95 \%$ dan tingkat kesalahan tidak lebih dari $10 \%$.

Jadi banyaknya sampel, dihitung sebagai berikut :

$$
\begin{aligned}
& \mathbf{N}=\frac{(\mathbf{Z})^{\mathbf{2}}}{\mathbf{e}}(\mathbf{P})(\mathbf{1}-\mathbf{P}) \\
& =\frac{(\mathbf{1}, \mathbf{9 6})^{\mathbf{2}}}{\mathbf{0 , 1}} \times \mathbf{0 , 2 5} \\
& =96,04
\end{aligned}
$$

Jadi jumlah sampel yang diambil dibulatkan menjadi 96 responden.

\section{ANALISIS DAN PEMBAHASAN}

\section{Analisis Regresi Linier Berganda}

Berdasarkan analisis dengan program SPSS 16 for Windows diperoleh hasil regresi berganda seperti terangkum pada tabel 4.10 berikut:

\begin{tabular}{|c|c|c|c|c|c|c|}
\hline \multirow{2}{*}{\multicolumn{2}{|c|}{ Model }} & \multicolumn{2}{|c|}{$\begin{array}{c}\text { Unstandardized } \\
\text { Coefficients } \\
\end{array}$} & \multirow{2}{*}{$\begin{array}{c}\begin{array}{c}\text { Standardized } \\
\text { Coefficients }\end{array} \\
\text { Beta }\end{array}$} & \multirow[b]{2}{*}{$\mathrm{T}$} & \multirow[b]{2}{*}{ Sig. } \\
\hline & & B & Std. Error & & & \\
\hline & (Constant) & -.222 & .793 & & -.280 & .780 \\
\hline & $\mathrm{X} 1$ & .169 & .063 & .203 & 2.704 & .008 \\
\hline & $\mathrm{X} 2$ & .384 & .072 & .412 & 5.315 & .000 \\
\hline & $\mathrm{X} 3$ & .324 & .073 & .350 & 4.430 & .000 \\
\hline
\end{tabular}

Tabel

Analisis regresi berganda

\section{Coefficients $^{\mathrm{a}}$}

a. Dependent Variable: Y

Sumber: Data primer yang diolah, 2020 
Berdasarkan tabel 4.10 diperoleh persamaan regresi berganda sebagai berikut:

$$
\mathrm{Y}=\mathbf{0 , 2 0 3} \mathrm{X}_{\mathbf{1}}+\mathbf{0 , 4 1 2} \mathrm{X}_{\mathbf{2}}+\mathbf{0 , 3 5 0} \mathrm{X}_{3} \text {. }
$$

Persamaan regresi tersebut mempunyai makna sebagai berikut:

(1) Kualitas Produk $\left(\mathrm{X}_{1}\right)=0,203$

Variabel kualitas produk berpengaruh positif, yang berarti bahwa semakin baik kualitas produk, maka semakin tinggi pula kemungkinan keputusan pembelian yang dilakukan oleh para pembeli

(2) Persepsi Harga $\left(X_{2}\right)=0,412$

Variabel persepsi harga berpengaruh positi, yang berarti bahwa semakin baik persepsi harga, maka semakin tinggi pula kemungkinan keputusan pembelian yang dilakukan oleh para pembeli.

(3) Promosi $\left(\mathrm{X}_{3}\right)=0,350$

Variabel promosi berpengaruh positif, yang berarti bahwa semakin baik promosi, maka semakin tinggi pula kemungkinan keputusan pembelian yang dilakukan oleh para pembeli.

\section{Pembahasan}

\section{Pengaruh Kualitas Produk terhadap Keputusan Pembelian}

Menurut Kotler dan Amstrong (2008) menyatakan bahwa "Semakin bagus kualitas produk yang ditawarkan maka dapat meningkatkan peluang kepada konsumen untuk melakukan keputusan pembelian".

Berdasarkan hasil penelitian, Kualitas produk memiliki pengaruh positif dan signifikan terhadap keputusan pembelian. Sehingga, semakin tinggi kualitas produk yang diberikan, maka semakin tinggi pula keputusan pembelian yang akan dilakukan oleh pembeli. Hal ini, didukung oleh penelitian yang dilakukan oleh Baruna Hadi Brata, Shilvana Husani dan Hapzi Ali (2017), yang menunjukan bahwa kualitas produk berpengaruh positif terhadap keputusan pembelian. Hal ini sejalan dengan penelitian yang dilakukan oleh Sarini Kodu (2013) yang menunjukan kualitas produk berpengaruh positif terhadap keputusan pembelian.

Dalam persaingan dunia usaha yang semakin ketat ini, perusahaan harus dilakukan research and development guna meningkatkan kualitas produk atas barang/jasa yang ditawarkannya, karena kualitas produk merupakan salah satu faktor penting bagi pertimbangan konsumen ketika hendak membeli sebuah produk. Dengan adanya kualitas produk yang baik, maka diharapkan dapat melakukan pembelian kembali kepada penyedia barang/jasa.

\section{Pengaruh Persepsi Harga terhadap Keputusan Pembelian.}

Harga merupakan salah satu unsur yang paling fleksibel dari bauran pemasaran yang lainnya, yang stabil dalam suatu kurun waktu tertentu dan juga dapat diubah sewaktu-waktu.

Berdasarkan hasil penelitian, terbukti bahwa persepsi harga berpengaruh positif dan signifikan terhadap keputusan pembelian. jadi, semakin harga yang ditawarkan terjangkau maka semakin meningkat pula peluang konsumen dalam mengambil 
keputusan pembelian. Hal tersebut, didukung oleh penelitian yang dilakukan oleh Sarini Kodu (2013) dengan judul "Harga, Kualitas Produk, dan Kualitas Pelayanan Pengaruhnya Terhadap Keputusan Pembelian Mobil Toyota Avanza" bahwa variabel persepsi harga berpengaruh positif terhadap keputusan pembelian dan sejalan dengan penelitian yang dilakukan oleh Charlie Bernando Halomoan Samosir, Arief Bowo Prayoga K. (2013) yang berjudul "Jurnal Pengaruh Persepsi Harga dan Promosi terhadap Keputusan Pembelian Konsumen Produk Enervon-C" dapat diambil kesimpulan bahwa variabel persepsi harga berpengaruh positif terhadap variabel keputusan pembelian.

Harga merupakan komponen yang sangat penting bagi calon konsumen ketika hendak memutuskan untuk membeli sebuah produk atau tidak. Ketika harga rendah, permintaan pasti akan meningkat. Begitu pula ketika harga dibandrol terlalu tinggi maka permintaan pasti akan menurun. Perusahaan harus benar-benar bijak dalam menentukan harga produk yang akan ditawarkannya, dimana harga yang ditetapkan harus sesuai dengan kualitas produk.

\section{Pengaruh Promosi terhadap Keputusan Pembelian}

Strategi penentuan promosi sangatlah penting dalam pemberian value kepada konsumen dan mempengaruhi citra produk serta keputusan pembelian konsumen untuk membeli, keputusan penetapan promosi begitu penting dalam menentukan seberapa baik layanan atau produk yan nantinya dinilai oleh konsumen. (Lupiyoadi, 2009).

Berdasarkan Hasil penelitian, terbukti bahwa promosi mempunyai pengaruh positif dan signifikan terhadap keputusan pembelian, sehingga dapat dikatakan bahwa semakin rutin melakukan promosi, maka akan meningkat pula peluang untuk calon konsumen mengambil keputusan untuk melakukan pembelian produk atau jasa yang ditawarkannya. Hal ini didukung oleh penelitian yang dilakukan oleh Charlie Bernando Halomoan Samosir, Arief Bowo Prayoga K. (2013) yang berjudul "Jurnal Pengaruh Persepsi Harga dan Promosi Terhadap Pembelian Konsumen Produk Enervon-C" menunjukan bahwa promosi berpengaruh positif terhadap keputusan pembelian. Hal ini sejalan dengan penelitian yang dilakukan oleh Baruna Hadi Brata, Shilvana Husani dan Hapzi Ali (2017) yang berjudul “The Influence of Quality Products, Price, Promotions, and Location to Product Purchase Decision on Nitchi At PT. Jaya Swarasa in Central Jakarta" yang dapat diambil kesimpulan bahwa variabel promosi berpengaruh positif terhadap variabel keputusan pembelian.

Kegiatan promosi perusahaan dalam mengkomunikasikan produknya kepada khalayak umum merupakan hal yang sangat penting. Strategi promosi bisa saja dilakukan berupa gabungan dari periklanan, penjualan perseorangan, ataupun melalui media online sebagai media promotor guna menyampaikan informasi tentang produk kepada calon komsumen yang didasari oleh product knowledge dan keunggulan atau keuntungan suatu produk. Dengan demikian perusahaan dapat mempengaruhi calon konsumen untuk mengambil keputusan pembelian atas suatu produk atau jasa yang ditawarkan. 


\section{KESIMPULAN}

Berdasarkan hasil penelitian yang telah dilakukan, maka dapat ditarik kesimpulan :

1. Kualitas produk memiliki pengaruh positif dan signifikan terhadap keputusan pembelian Wellblue Alkaline Water Pitcher. Jadi, dapat disimpulkan bahwa ketika kualitas produk semakin meningkat maka akan meningkat pula keputusan pembelian Wellblue Alkaline Water Pitcher.

2. Persepsi harga memiliki pengaruh positif dan signifikan terhadap keputusan pembelian Wellblue Alkaline Water Pitcher. Jadi, dapat disimpulkan bahwa ketika harga yang ditawarkan terjangkau dan sesuai dengan kualitas produk, maka akan meningkatkan keputusan pembelian Wellblue Alkaline Water Pitcher.

3. Promosi memiliki pengaruh positif dan signifikan terhadap keeputusan pembelian Wellblue Alkaline Water Pitcher. Jadi, dapat disimpulkan bahwa ketika semakin meningkat promosi sebuah produk, maka akan semakin meningkat pula keputusan pembelian Wellblue Alkaline Water Pitcher.

4. Berdasarkan hasil perhitungan koefisien determinasi ganda, didapati bahwa besarnya pengaruh kualitas produk, persepsi harga, dan promosi terhadap keputusan pembelian Wellblue Alkaline Water Pitcher adalah sebesar 59,5\%.

\section{Saran}

Berdasarkan hasil penelitian yaitu kualitas produk, persepsi harga dan promosi ternyata secara positif dan signifikan berpengaruh terhadap meningkatnya keputusan pembelian. Dengan demikian variabel-variabel tersebut harus lebih diperhatikan oleh pihak manajemen perusahaan meliputi :

1. Berdasarkan hasil penelitan pada variabel kualitas produk, dengan nilai terendah terdapat pada indikator nomor 1 yaitu kualitas bahan baku Wellblue Aklanie Water Pitcher. Sebaiknya perusahaan memiliki perhatian yang lebih terhadap kualitas bahan baku produk. Karena saat ini Wellblue Alkaline Water Pitcher masih menggunakan fiber plastic, diharapkan kedepan bahan baku plastik dapat dikurangi dan diganti dengan material yang lebih ramah lingkungan, sehingga konsumen lebih nyaman dan merasa aman ketika menggunakan Wellblue Alkaline Water Pitcher sebagai teko air minum kesehatan keluarga.

2. Berdasarkan hasil penelitian pada variabel persepsi harga, dengan nilai terendah terdapat pada indikator nomor 2 yaitu harga terjangkau. Perusahaan sebaiknya memperhatikan harga produk kompetitor, agar harga yang ditawarkan kepada konsumen tidaklah terlalu mahal. Sehingga perusahaan mampu menentukan harga yang tepat terhadap nilai jual Wellblue Alkaline Water Pitcher, guna meningkatkan keputusan pembelian konsumen.

3. Berdasarkan hasil penelitian pada variabel promosi dengan nilai terendah pada indikator nomor 3 yaitu memasarkan produk Wellblue Alkaline Water Pitcher secara 
langsung. Sebaiknya perusahaan merancang suatu konsep pemasaran secara langsung (direct selling) yang lebih efektif dan menarik, dari cara demonstrasi produk dan menampilkan keunggulan produk secara langsung. Apabila hal ini dapat diimplementasikan dalam perusahaan secara berkesinambungan niscaya dapat meningkatkan volume penjualan dan pendapatan perusahaan.

\section{Keterbatasan Penelitian}

Dalam penelitian ini terdapat beberapa keterbatasan dalam penelitian, yaitu sebagai berikut :

1. Respon yang rendah dari responden, ditandai dengan banyaknya responden dengan tidak langsung mengisi kuisioner sehingga membutuhkan waktu yang lama dalam pengumpulan data.

2. Variabel yang digunakan dalam peneitian ini hanya kualitas produk, persepsi harga, promosi terhadap keputusan pembelian. Kemunginan masih ada variable lain yang turut berpengaruh terhadap keputusan pembelian Wellblue Alkaline Water Pitcher

3. Hasil penelitian ini tidak dapat digeneralisasikan untuk kasus lain diluar objek penelitian.

\section{Agenda Penelitian Mendatang}

Untuk penelitian mendatang perlu dilakukan pembenaha, inovasi dan pengembangan lebih lanjut dalam penelitian ini sehingga dapat memberikan hasil yang lebih baik, antara lain dengan menambah variabel independent yang mempengaruhi keputusan pembelian Wellblue Alkaline Water Pitcher.

\section{DAFTAR PUSTAKA}

Achmad, Zainul Arifin, dkk. 2014. "PengaruhPromosiOnline dan PersepsiHargaTerhadap Keputusan Pembelian (Survei Pada PelangganArykaShop di Kota Malang)". FakultasIlmuAdministrasi, UniversitasBrawijaya, Malang.

Anggarisma, galih (2015) Analisis Pengaruh Kualitas Produk, Harga dan Promosi Tehadap Keputusan Pembelian Handphone Merek Samsung (Studi Kasus Mahasiswa Universitas Muhammadiyah Surakarta). Skripsi thesis, Universitas Muhammadiyah Surakarta.

Baruna, ShilvanaHusani, dkk. 2017. "The Influence of Quality Products, Price, Promotions, and Location to Products Purchase Decision on Nitchi At PT. Jaya Swara Agung in Central Jakarta". FakultasEkonomi dan Bisnis, UniversitasMercuBuana, Jakarta. 
Charlie, AriefBowo, dkk. 2015. "JurnalPengaruhPersepsiHarga Dan PromosiTerhadap Keputusan PembelianKonsumenProdukEnevon-C”. FakultasEkonomi dan Bisnis, UniversitasMercuBuana, Jakarta.

Daryanto. 2012. Manajemen Produksi. Bandung: PT. Sarana Tutorial Nurani. Sejahtera

Ferdinand. (2013). Metode Penelitian Manajemen. Semarang. Badan. Penerbit Universitas Diponegoro.

Ghozali, Imam, 2011, AplikasiAnalisis Multivariatedengan program SPSS, Badan PenerbitUniversitas Semarang.

Kotler, Philip. 2012. Prinsip-PrinsipPemasaran, PenerbitErlangga, Jakarta.

Kotler, Philip, dan Gary Armstrong. 2012. Prinsip-PrinsipPemasaran.PenerbitErlangga, Jakarta.

Lupiyoadi, R. dan Hamdani, A. 2009. Manajemen Pemasaran Jasa. Jakarta: Salemba Empat

Mariana. 2015. "PengaruhKualitasProduk dan HargaTerhadap Keputusan PembelianProduk Pada Industri UKM Amplang UD. SinarRejeki di Samarinda". JurusanEkonomi dan Bisnis, UniversitasMulawarman, Samarinda.

Philip Kotler, 2002, Manajemen Pemasaran, Edisi Millenium, Jilid 2, PT Prenhallindo, Jakarta

PrabaSulistyawati. 2010. "AnalisisPengaruh Citra Merek dan KualitasProdukTerhadap Keputusan Pembelian Laptop Merek Acer di Kota Semarang". FakultasEkonomiManajemen, UniversitasDiponegoro, Semarang.

Tika HapsahroniPanjaita. 2016. 'Personal Selling Influence on Decision to Purchase (PT MilleiumPharmaconRetrospectiva Case Series Study International Tbk Branch Bandung)". JurusanManajemenPemasaran, Universitas Telkom, Bandung.

Sarini Kodu. 2013. "Harga, KualitasProduk, dan KualitasPelayananPengaruhnyaTerhadap Keputusan Pembelian Mobil Toyota Avanza". FakultasEkonomi dan BisnisJurusamManajemen, Univeritas Sam Ratulangi, Manado. 